\title{
COMMUNICATIONS
}

\section{LARVAL GRANULOMATOSIS OF THE RETINA DUE TO TOXOGARA}

\author{
BY \\ NORMAN ASHTON \\ Department of Pathology, Institute of Ophthalmology, University of London
}

NEMATODES have so rarely been demonstrated in intra-ocular disease that they are seldom considered in differential diagnosis as agents of possible significance, and this is especially true in temperate climates where such cases as have been reported are regarded as ophthalmological curiosities. That this view should be revised was first suggested by the important observations of Wilder (1950), who, in a histological study of pseudogliomata, found nematode larvae, or their residual hyaline capsules, in about half the cases, and in the remainder tissue-reactions characteristic of nematode endophthalmitis. Although Wilder's material was selected by reason of its uniform clinical and pathological picture, the findings nevertheless justified her conclusions that nematodes probably played an important part in causing blindness in American children and that this possibility was being overlooked.

The parasites had been identified as third-stage larvae of the hookworm and consequently the interest which Wilder's report aroused in countries where ankylostomiasis is a rarity was largely academic, but about this time similar work was progressing in other fields. Beaver, Snyder, Carrera, Dent, and Lafferty (1952) were investigating three cases with eosinophilic granulomatous lesions of the liver, and in a liver biopsy from one case they found a larval nematode of the genus Toxocara, the common ascarid of dogs and cats. Considerable attention then became focused on host-foreign nematodes as agents capable of producing human disease, and larvae of Toxocara, usually in the second stage, have since been demonstrated in man widely scattered throughout the viscera and central nervous system (Beautyman and Woolf, 1951; Brill, Churg, and Beaver, 1953; Dent and Carrera, 1953; Dent, Nichols, Beaver, Carrera, and Staggers, 1956), while considerable experimental work has been done which is of great value in identifying the larvae in tissues (Smith and Beaver, 1953; Sprent, 1954; Schacher, 1957). Armed with this new knowledge, Nichols (1956a) re-examined five of the cases of nematode endophthalmitis from Wilder's series and was able to identify the worms, with certainty in four of them, not as third-stage larvae of the hookworm, but as second-stage larvae of Toxocara canis, thus showing for the 
first time that this animal nematode, common in dogs throughout the world, is capable of infecting the human eye. A further case of endophthalmitis in a child aged $4 \frac{1}{2}$ years which was due to infestation with Toxocara canis, but was also diagnosed clinically as retinoblastoma, has recently been reported from California by Irvine and Irvine (1959).

The purpose of the present paper is to show that this condition may occur as readily in the United Kingdom as in the United States, for we are now able to report four cases of intra-ocular nematode infestation, wherein the larvae of Toxocara canis have actually been demonstrated. From this material it is also possible to describe a new clinico-pathological entity quite distinct from endophthalmitis, namely the formation of solitary localized tumours in the retina which may or may not be associated with any other significant intra-ocular abnormality.

\section{Case Reports}

Case 1, a girl aged 8 years, attended Moorfields Hospital under the care of Mr. Frederick Ridley in August, 1952, with a history of deterioration of vision over a period of 3 years and slight photopsia for one year. A macular mass had recently been noted in the right eye at the school clinic. There was a past history of ptosis at birth with gradual recovery, pneumonia at 4 years old, and tonsillectomy at 7 years old.

Examination.-The visual acuity was $6 / 60$ in the right eye and $6 / 5$ (with $+0.75 \mathrm{D}$ sph.) in the left.

The right fundus showed a creamy-white, umbilicated tumour at the macula with some vitreous opacity and choroidal disturbance at 6 o'clock. The child was admitted for investigation and a fundus painting was made (Fig. 1, opposite).

A chest $x$-ray, Wassermann reaction, Kahn test, and gonococcal complement-fixation test were all negative. A Mantoux test was negative up to $1 / 100$.

By September, 1952, the tumour had increased in size and was thought to be a retinoblastoma; staff opinion favoured excision and this was carried out in October, 1952.

\section{Pathology}

Macroscopical Examination.-The globe was opened horizontally. Situated at the macula there was a small, raised yellowish mass with a white centre; it was well-demarcated and completely localized. Except for delicate whitish scar tissue in the region of the ciliary body inferiorly, the rest of the eye appeared to be normal.

Microscopical Examination.-The cornea, corneo-iridic angle, iris, ciliary body, and lens appeared normal. Anteriorly on the temporal side the retina showed advanced cystic degeneration extending from the equator to the ora serrata where the retina was dragged forward into a small fibrinoid deposit lying in the vitreous on the pars plana. Situated at the macula there was a well-defined mass of fibrous tissue extending inwards into the vitreous through the fovea centralis, and outwards to merge with Bruch's membrane and the choroid (Fig. 3, overleaf). On either side the retina was folded and shallowly detached with a small sub-retinal exudate. Within the fibrous mass there was a focal and diffuse infiltration with chronic inflammatory cells, among which numerous eosinophils could be seen. A similar but denser infiltration was present in the immediately adjacent choroid and the pigment epithelium had migrated into the fibrous mass. Apart from these changes the eye was histologically normal.

When the above report was written it was considered that the fibrous mass at the macula was probably due to injury, especially in view of the fibrinous organization in the anterior vitreous which suggested old haemorrhage. However, no 
LARVAL GRANULOMATOSIS OF RETINA DUE TO TOXOCARA

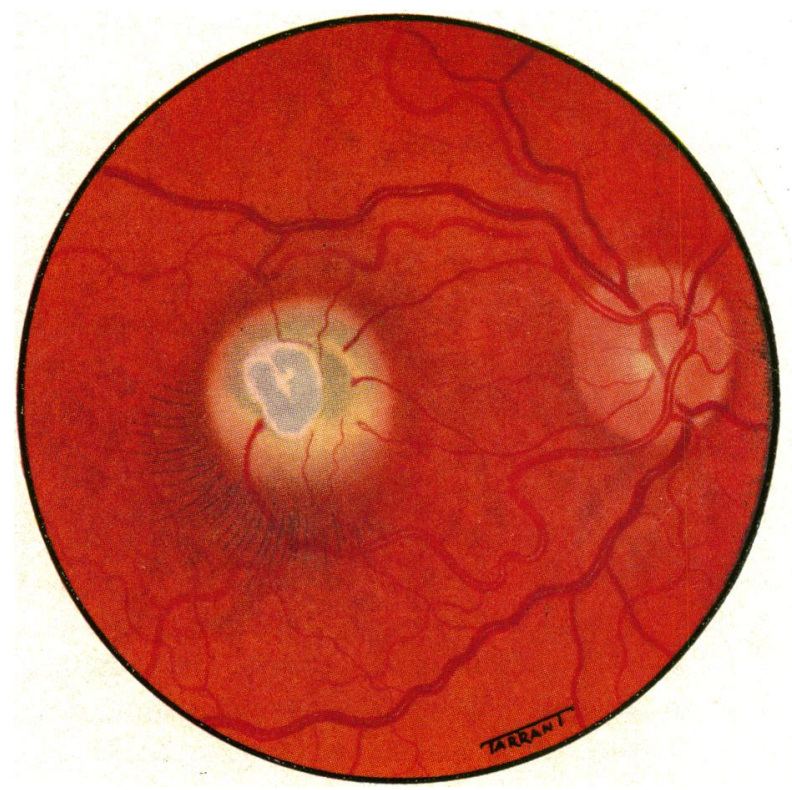

Fig. 1.-Case 1, appearance of right fundus.

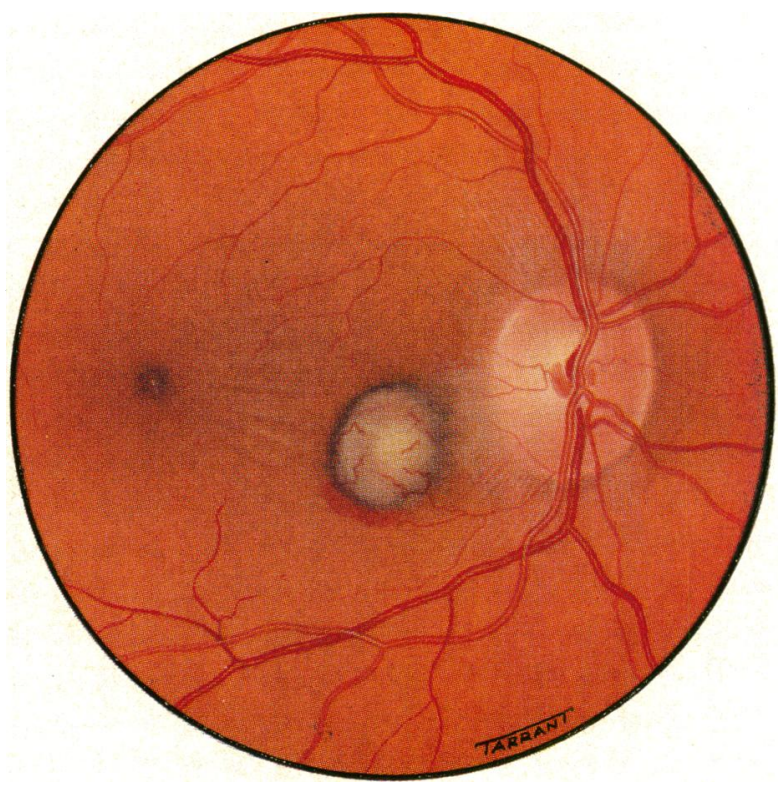

Fig. 2.-Case 2, appearance of right fundus.

Facing page 130 


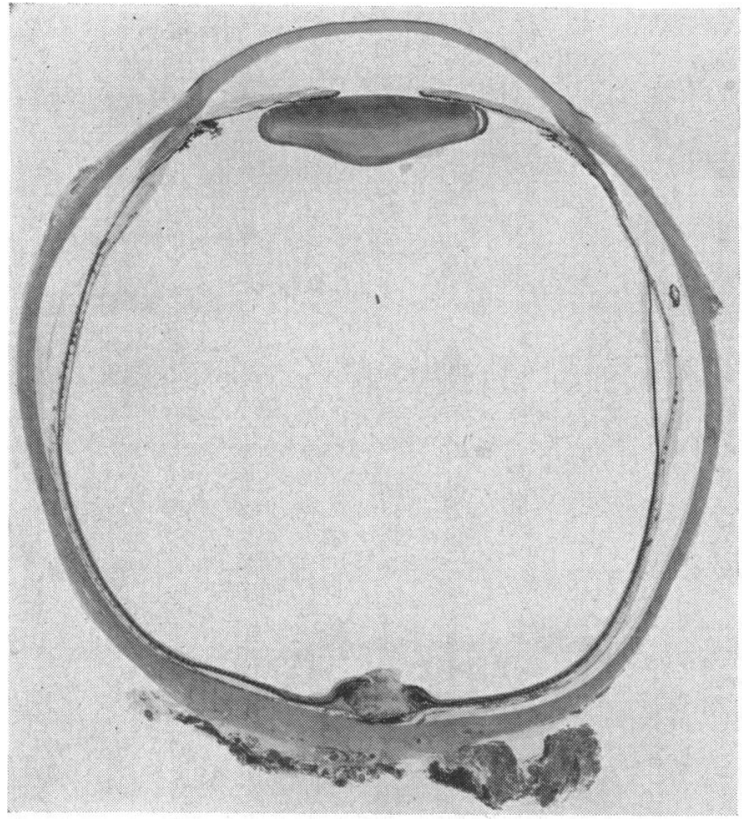

Fig. 3.-Case 1, section of right eye, showing a fibrous granuloma at the macula, and cystic degeneration of temporal retina anteriorly. Celloidin section. Haematoxylin and eosin $\times 3.75$.

history of injury was obtainable from the mother and no satisfactory diagnosis could be made. Seven years afterwards (in 1959) serial sections were cut from this eye for demonstration purposes. ${ }^{*}$ In five of the sixty stained sections examined, fragments of a nematode larva, resembling that of the genus Toxocara, were found lying in the centre of the fibrous mass where there was fibrinoid necrosis but no giant-cell reaction (Figs 4, 5, 6, 7).

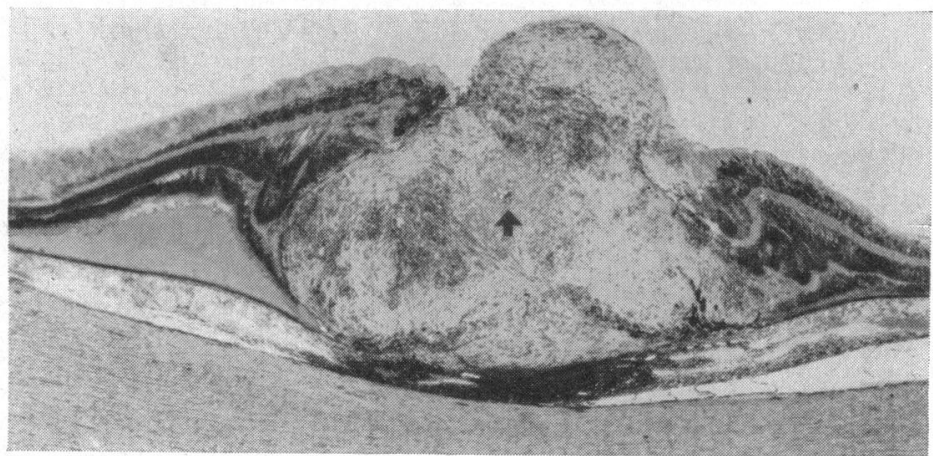

FIG. 4.- Higher-power view of macular granuloma (seen in Fig. 3), showing at the centre fragments of a nematode larva (arrow). A dense inflammatory infiltration is present in the subjacent choroid. $\times 21$.

* This was in response to an invitation to demonstrate a case to the American Ophthalmic Pathology Club, at which 35 sections were required-one for each member. Preparation of these 35 slides revealed the nematode; hence this first case was discovered purely by chance. 


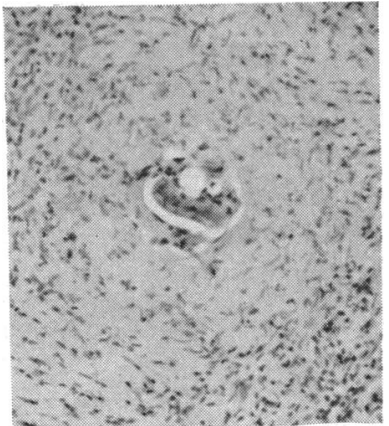

Fig. 5.-Larval fragments lying in an area of fibrinoid necrosis in the centre of the tumour shown in Fig. $4 . \quad$ No giant cells were present. $\times 102$.

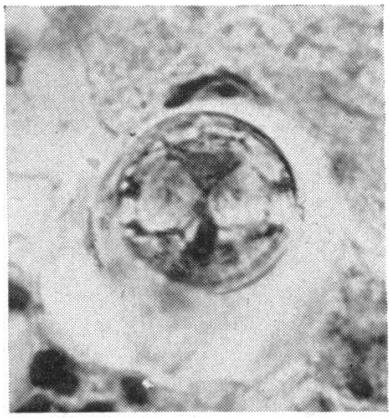

Fig. 6.-Transverse section through larval fragment (Case 1) showing excretory columns, intestine, and lateral alae. Compare Fig. 24(b).

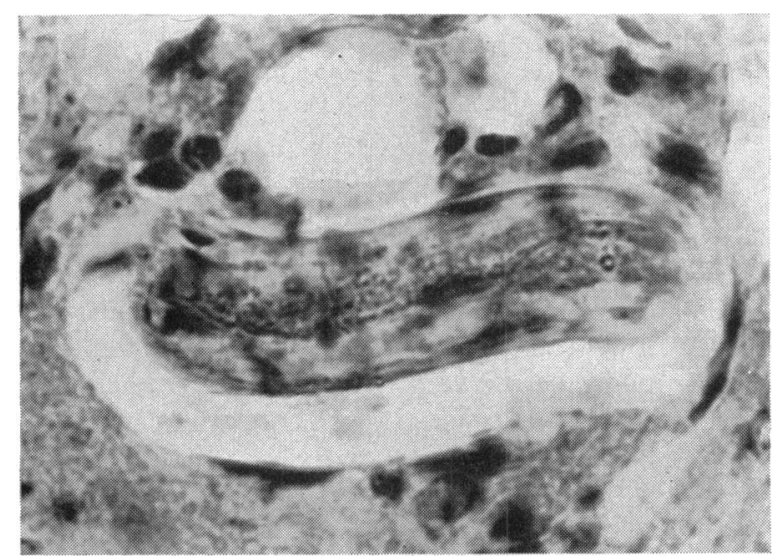

FIG. 7.-High-power view of Fig. 5, showing longitudinal section of larval fragment. $\times 660$.

In view of these findings the patient was re-examined for any evidence of parasitic infection, although little was to be expected so long after enucleation. No eosinophilia or other evidence of parasitic infection could be found, and no history of old infection was obtained from the mother. The family had kept a dog when the child was 8 years old, which is about the time when the eye trouble first appeared; there was no known contact with cats.

The five sections were submitted to Prof. J. J. C. Buckley, of the Department of Parasitology, London School of Hygiene and Tropical Medicine, who reported as follows:

"The nematode larva in the macular mass is identifiable as that of Toxocara canis by means of the key and illustrations provided by Nichols (1956a). Lateral alae (single) are visible in both the transverse sections of the larva, and its diameter of 22-22.5 microns is the maximum for a second-stage larva of $T$. canis. One transverse section (Fig. 6) shows the intestine and excretory columns exactly as illustrated by Nichols (Fig. 24b)." 
Case 2, a boy aged 16 years, attended the Bristol Eye Hospital under the care of Mr. P. Jardine in February, 1950, complaining of blurring of vision in the right eye since the previous December. One week before the onset of this symptom he had been punched on the nose during a boxing contest.

Examination.-The visual acuity was $6 / 12$ in the right eye and $6 / 5$ in the left.

The anterior segment of the right eye was normal and the media clear, but in the fundus just lateral to and slightly below the optic disc was a circular, greyish-white, raised area, approximately one disc diameter in size and bearing fine vessels on its surface. At its lower edge there was a small area of haemorrhage (Fig. 2, above, opp. p. 130). With a 10-mm. object at one metre, the visual field showed a defect continuous with the blind spot and corresponding in situation with the tumour. No arcuate scotoma was present.

The left eye was normal in all respects. The Wassermann reaction and Kahn test were negative and a full blood count and the erythrocyte sedimentation rate were normal. $X$ rays of the skull, orbits, optic foramina, and chest showed no abnormality. Lumbar puncture was not performed, but the visiting physician considered that there was no central nervous disease.

The majority opinion of the staff at Bristol Eye Hospital was in favour of a retinal neoplasm, and early in March, 1950, the boy was referred to Moorfields, where the following opinions were expressed:

Organizing choroidal haemorrhage; inflammatory lesion; juvenile exudating macular degeneration (Junius); neoplasm.

It was recommended that the case be watched carefully and that echinococcosis be excluded. The Casoni test was carried out and was negative.

During the next 3 months the visual acuity gradually deteriorated to a bare $1 / 60$ and the patient complained of increasing pain in and around the eye. The tumour was considered to be enlarging, and stippling and exudate appeared around the macula with retinal swelling between the tumour and the macula. Binocular examination of the fundus showed the tumour to be projecting well forward, being transparent and gelatinous in appearance superficially and opaque-white in its deeper part. Enucleation was performed in June, 1950.

\section{Pathology}

Macroscopical Examination.-The globe was opened horizontally to reveal a small, greyish-white, roughly circular mass about the size of the disc, projecting from the temporal border of the disc and extending towards the macula and slightly downwards.

Microscopical Examination.-The cornea, anterior chamber, iris, lens, and ciliary body presented no abnormalities. Immediately adjacent to the temporal border of the disc there was a mass of fibrous tissue which was largely hyalinized and contained strands and clusters of chronic inflammatory cells, scattered pigment cells, and practically no vessels (Fig. 8, overleaf). This mass of tissue had developed between Bruch's membrane and the rod and cone layer. The overlying retina was not invaded but simply pushed away from the pigment layer, and there were small quantities of subretinal exudate on both sides of the mass. The detachment extended to the nasal border of the macular region but not into the macula itself. In the adjacent retina, exudates were present in the outer plexiform layer, while the choroid beneath the mass showed a moderate degree of thickening from chronic inflammatory infiltration in which a few eosinophils were present.

When the above report was written, this case was thought to be a minor form of Coats's disease or possibly an example of juvenile disciform degeneration. In view of its similarity to Case 1 , however, and because of the very definite history of injury, the lesion was later re-categorized as a traumatic proliferative chorioretinopathy. The subsequent finding of a larva in Case 1 suggested that serial sections of this eye might be equally rewarding, and further sections were cut in 
1959, 9 years after enucleation. In two of the 26 serial sections examined, fragments of a nematode larva were found; these were seen in both longitudinal and cross

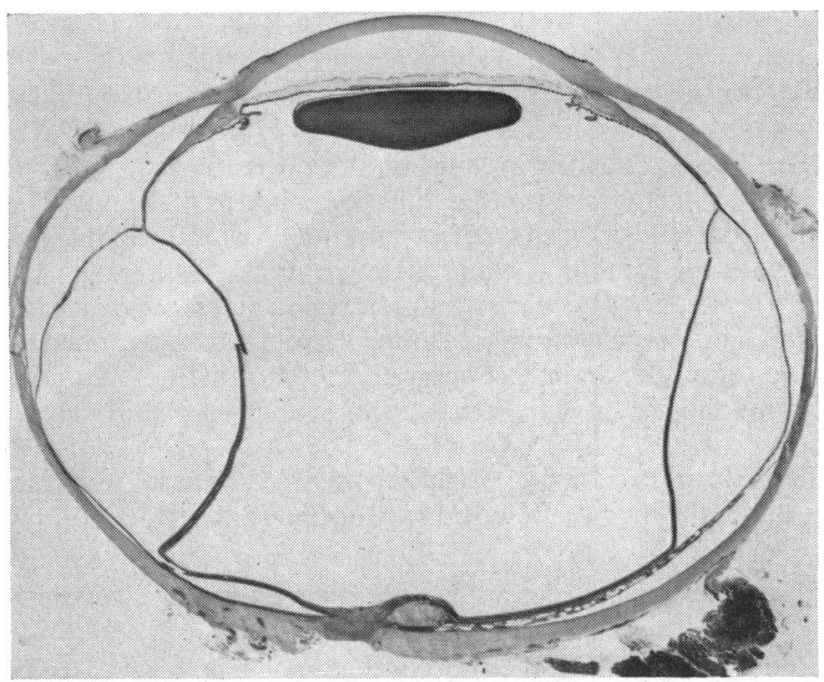
section and were found lying in a small zone of necrotic eosinophilic fibrinoid material in the centre of the juxtapapillary tumour. No giant cells were present (Figs 9, 10, 11, and 12).

Fig. 8.-Case 2, section of right eye, showing a fibrous granuloma immediately adjacent to the temporal border of the disc. Retinal detachment is due to artefact. Celloidin section. Haematoxylin and eosin. $\times 3 \cdot 75$.

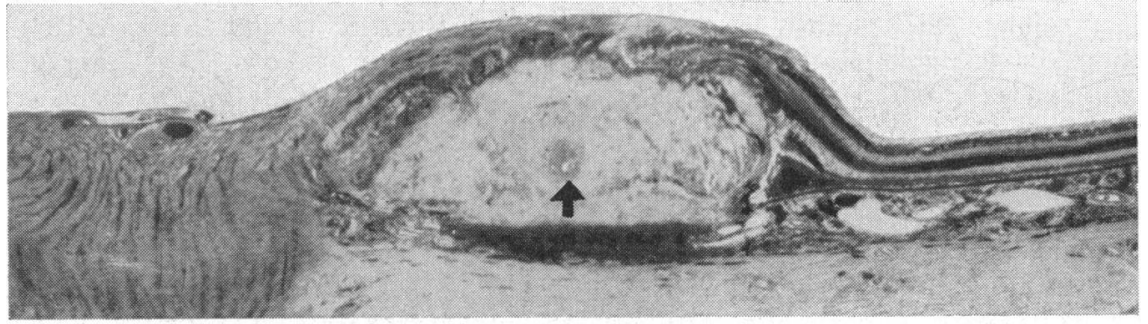

Fig. 9. - Higher-power view of granuloma (seen in Fig. 8), showing at the centre fragments of a nematode larva (arrow). A chronic inflammatory infiltration is present in the subjacent choroid. $\times 20$.

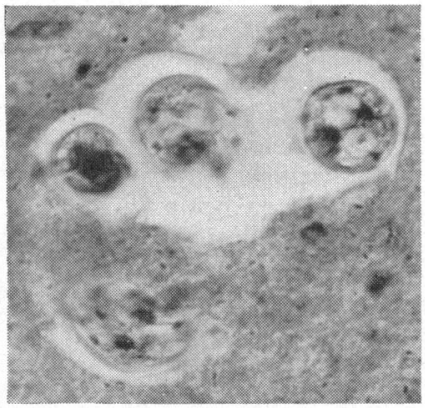

Fig. 10.-Transverse section of larva lying in necrotic fibrinoid material (Case 2). $\quad \times 375$.

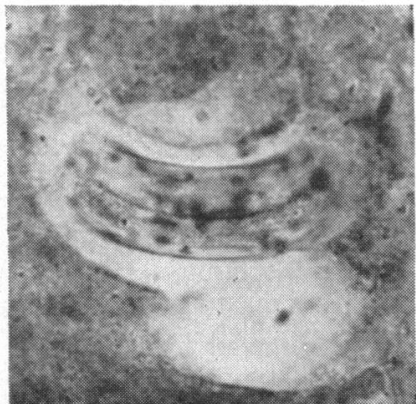

FIG. 11.-Longitudinal section of larval fragment (Case 2). $\times 375$.

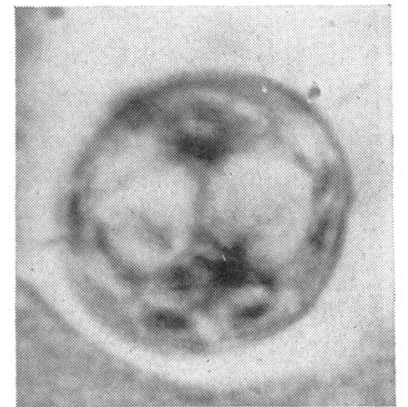

FIG. 12.-High-power view of transverse section of larval fragment seen in Fig. 10, showing similar structure to that in Fig. 6. Compare Fig. 24(b). $\times 1185$. 


\section{LARVAL GRANULOMATOSIS OF RETINA DUE TO TOXOCARA 135}

As a result of this finding $\mathrm{Mr}$. Jardine kindly saw the patient again to inquire into any history of animal contact; although the patient had never had a dog of his own he had been in close contact with a neighbour's dog. The blood count was not repeated since at the time of enucleation there was no eosinophilia, and, as already indicated, the general physical examination at that time was entirely negative. Apart from the eye, therefore, there was no clinical evidence of visceral larva migrans.

For exact identification of the larva the sections were submitted, in the absence of Prof. Buckley, to Dr. J. N. Oldham, Reader in Veterinary Parasitology, University of London, who reported as follows:

"In one slide there is a small portion, in longitudinal section, of a nematode, the diameter of which is $0.018 \mathrm{~mm}$. The other slide shows three portions of the nematode, one portion in true cross-section, the second slightly oblique, and the third in more or less longitudinal section. Using the portion in true cross-section only, its diameter is $0.022 \mathrm{~mm}$. Sprent (1958) gives the diameter of second-stage larvae of Toxocara canis as varying from 0.018 to $0.024 \mathrm{~mm}$. and the measurements I have made of the portions in the eye sections fall within this range."

Case 3, a boy aged 6 years, was first seen in 1953 as an infant by Mr. A. E. Wilson of Taunton for a right convergent strabismus. The case was subsequently treated in the usual orthodox way by means of glasses to correct the hypermetropia and astigmatism, intermittent occlusion, and surgery. He was operated on in 1955, 1956, and 1958. In August, 1958, the orthoptist reported that the child was fixing mainly with the right eye and that the visual acuity was $6 / 18$ in the right eye and 6/12 in the left with the $E$ test, but by December, 1958, the visual acuity in the right eye had dropped to 6/60, while that in the left had improved to 6/9. As there was no response to occlusion, the orthoptist referred the patient back in May, 1959.

Examination.-The right eye had become about $2 \frac{1}{2}$ dioptres more hypermetropic, while the left remained approximately the same as previously. Ophthalmoscopic examination revealed a white mass to the temporal side of the right optic disc forming an obvious swelling extending into the vitreous (Fig. 13). Mr. Wilson was confident that this lesion had not been present in August, 1958, and he referred the boy to Mr. C. I. Phillips of the Bristol Eye Hospital for a second opinion. There the erythrocyte sedimentation rate was normal, the Wassermann reaction, Kahn test, and

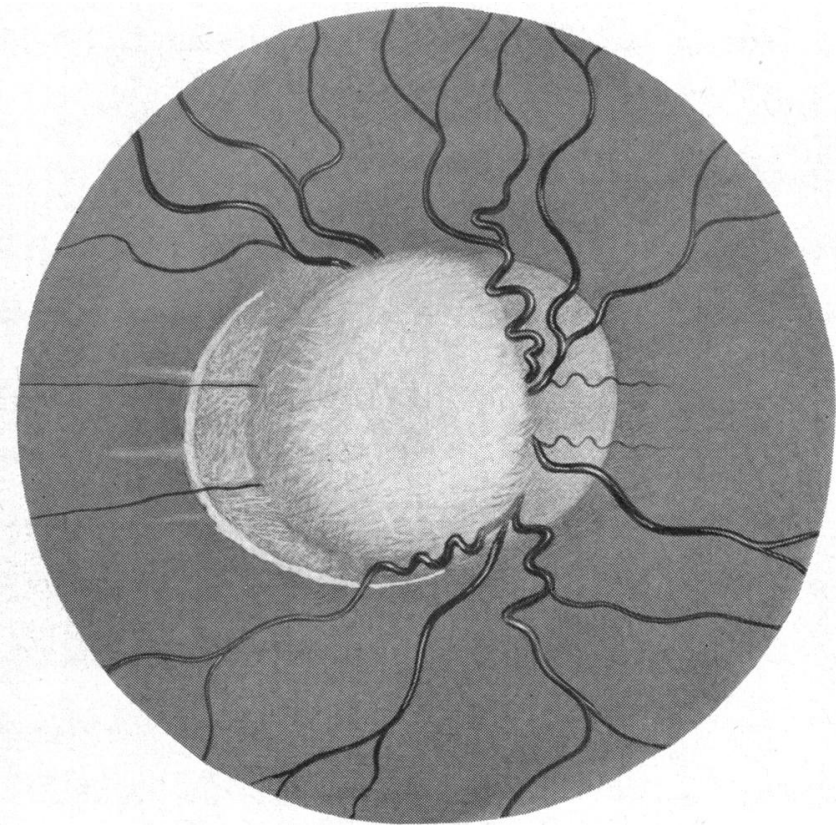

FIG. 13.-Case 3, appearance of right fundus. 
urine tests were negative, the toxoplasma dye test was negative at $1 / 16$ and the complement-fixation test negative at $1 / 4$.

As the lesion appeared to have increased in size the probability of retinoblastoma seemed strong and enucleation was performed in June, 1959.

Pathology

Macroscopical Examination.-The globe was opened horizontally to reveal a small circular white area situated immediately above and lateral to the disc. Transverse sections of the optic nerve showed no abnormality.

Microscopical Examination.-The main pathological change in this eye was to be seen in the papillo-macular region, where there was a thickened plaque of tissue extending from the temporal papillary margin for a distance of about 3 disc diameters. The plaque consisted of folded retinal tissue, which included the macula in its lateral half and the margin of the laterally-displaced disc in its medial half. Centrally there was a shallow concavity containing a mass of fibrous tissue infiltrated with plasma cells, lymphocytes, and a moderate number of eosinophils; there were also one or two foci of epithelioid cells and large foreign-body giant cells. The underlying choroid showed no inflammatory reaction and the vitreous only a small quantity of exudate (Figs 14, 15, and 16).

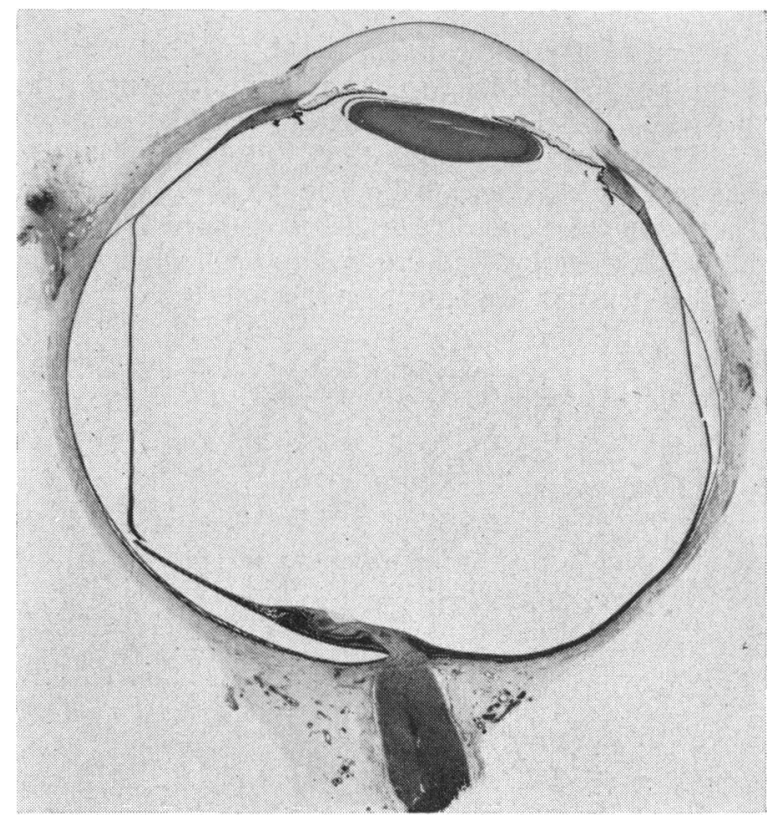

Fig. 14.-Case 3, section of right eye, showing a thickened plaque of tissue in the papillo-macular region distorting the optic nervehead. Celloidin section. Haematoxylin and eosin. $\times 3.75$.

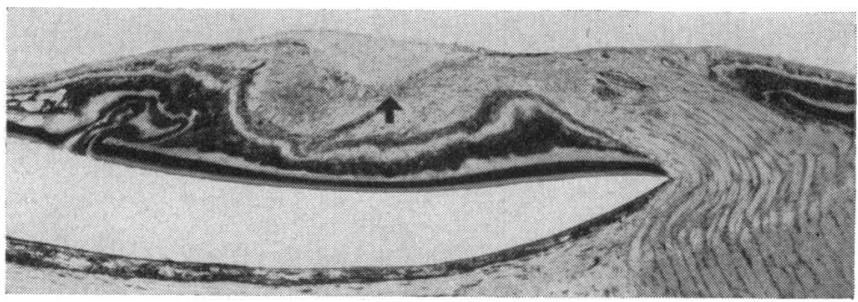

Fig. 15.-Higher-power view of the lesion shown in Fig. 14. The plaque consists of folded retinal tissue forming a shallow concavity containing a mass of fibrous tissue. Arrow indicates the site of the nematode larval fragment. $\quad \times 36$. 


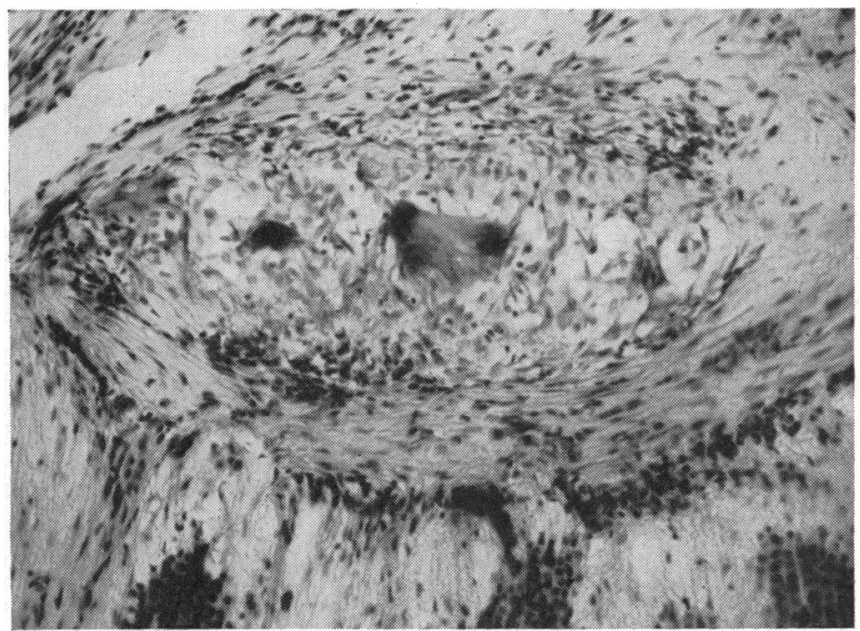

Fig. 16.-Higher-power view of an area of the granuloma shown in Fig. 15. There is a focus of epithelioid cells and foreign body giant cells. $\times 94$.

Apart from a mild inflammatory reaction in the sclera at the site of the old squint operations, the remainder of the eye showed no histological abnormality, but five of the eighty serial sections made through the affected area showed a longitudinal section of a fragment of a nematode larva lying, with a clearly defined capsule, in a tubular space at the centre of the main inflammatory focus (Fig. 17).

Fig. 17.-High-power view of adjacent area to that seen in Fig. 16, showing longitudinal section of larval fragment lying in tubular space at site indicated in Fig. 15. $\times 660$.

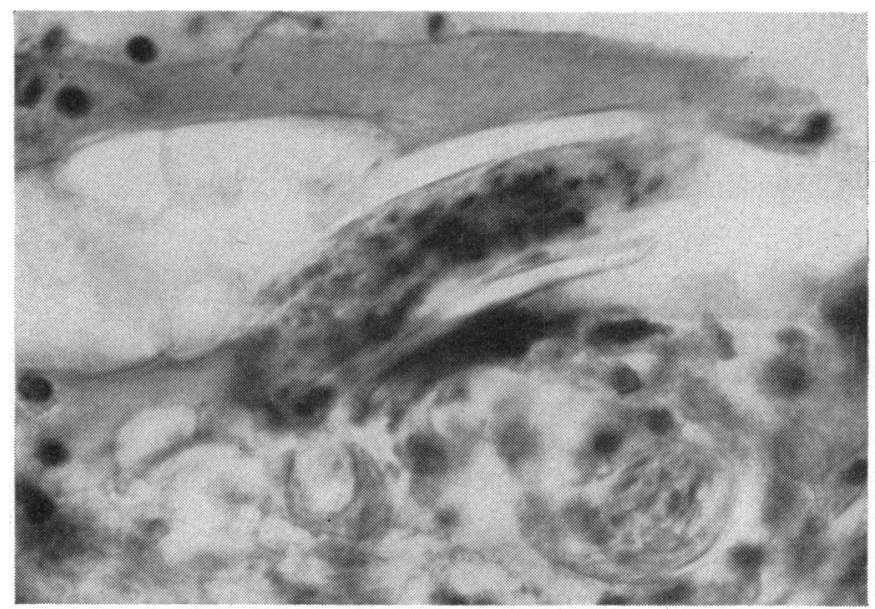

In view of these findings the patient was re-examined and further investigations carried out. The general practitioner reported that there had been no history of unexplained fever, jaundice, pulmonary symptoms, or malaise. The boy's past illnesses were whooping cough and thrush, 1954, urticaria, 1955, sore throat, 1956, and measles and ? fungus infection of knee and elbow, 1958; 3 months after the enucleation he had developed a cervical adenitis apparently due to a nasopharyngeal infection, which recovered on sulphonamides. The family kept a cat and a bird, but no dog. A blood count carried out in August, 1959, showed a very slight eosinophilia:

Haemoglobin 81 per cent. (11.8 g./100 ml.), W.B.C. 7,000 per c.mm., Neutrophils 46 
per cent. (3,220 per c.mm.), Eosinophils 7 per cent. (490 per c.mm.), Lymphocytes 45 per cent. (3,150 per cmm.), Monocytes 2 per cent. (140 per c.mm.).

For identification of the larva the three slides were submitted to Dr. J. N. Oldham who reported as follows:

"Each of the three slides shows a single portion of a nematode in partial longitudinal section. Where the body cuticle could be well identified, diameter measurements were made, and these varied from 0.018 to $0.024 \mathrm{~mm}$. a range which coincides with that given by Sprent (1958) for Toxocara canis. If one relies on diameter measurements alone, this larva is more likely to be that of Toxocara canis than that of Toxocara cati."

Case 4, a boy aged 4 years, was first seen by the school oculist at the age of 3 years for a right squint which had appeared at the age of 18 months. A grey mass with circular haemorrhages was found at the posterior fundus and the boy was referred to Mr. W. O. G. Taylor of Kilmarnock for examination under anaesthetic. The findings were confirmed, and, as the tumour appeared to be growing out of the optic nerve head, it was thought to be a glioma of the nerve and the patient was sent to the neuro-surgical unit of the Killearn Hospital. Here the late Dr. John Fraser reported as follows:

"This child has a squint of the right eye and on attempting to fix, the eye is rather elevated. The right eye is white, with a persistent pupillary membrane, a moderately dilated pupil, and clear media. At the nerve head and extending into the lower temporal region, there is an irregular mass of scar tissue; below this and adherent to it, there is a localized detachment of the retina and there is a haemorrhage above. The retinal vessels are irregular at the lower margin of the detached retina and are rather numerous in appearance. Above the disc and in the lower nasal quadrant near the disc, there are white exudates which appear to be more choroidal than retinal. There is no appreciable abnormality in the periphery of the fundus.

The picture is not exactly that of a retinoblastoma with extension into the nerve head, and if one considers it to be a glioma of the nerve with extension into the eye, one would have expected to see some more proptosis and more engorgement of the retinal vessels with an appearance more of a choked disc than is actually present. The other eye appears healthy."

Dr. Fraser suggested that the case be further investigated and that yet further ophthalmological opinion be obtained. $X$ rays of the orbit were negative and in particular the optic foramina were normal in size. The Wassermann reaction was negative. A blood count showed R.B.C. 5,200,000 per c.mm., Haemoglobin 13.2 g. (Sahli), W.B.C. 10,800 per c.mm. A differential count was not done. The erythrocyte sedimentation rate was somewhat raised, $18 \mathrm{~mm}$./hr (Wintrobe). Toxoplasma tests on the sera of the child and his mother were negative.

The child was then referred to Dr. John Marshall of Glasgow who reported as follows:

"This small child whom I saw this morning (December 5, 1955) for a second opinion has an appearance in the fundus which is suggestive of glioma exophytum near the optic nerve head. I think there is no doubt that the right treatment is to remove the eye. I am less sure about the necessity for a transfrontal section of the nerve, but $I$ am sure that Dr. W. O. G. Taylor's observation that the tumour is rapidly growing and the fact that the masses lie so near the nerve head make this a reasonable procedure; the eye has very poor vision and is likely to become blind in any case, so that no point would be served by attempting to retain it. I am sure that surgical intervention would increase the expectation of life in the event of this being a glioma."

Mr. J. Sloan Robertson, neurosurgeon, therefore decided to excise the optic nerve as far back as the chiasma, but at operation he found no suggestion of a tumour in the nerve and section of the nerve was normal. Dr. Fraser later enucleated the eye early in 1956, and a section was subsequently sent by Dr. John A. Milne, Area Pathologist of Ayrshire, to the Institute of Ophthalmology in June, 1956, for a second pathological opinion. 
Section for Opinion.-The only significant abnormality to be found in this single section was to be seen in the posterior fundus on the temporal side, where there was a fibrous tumour embedded in the macula, the adjacent retina being shallowly detached, folded, and adherent to the lateral borders of the fibrous mass (Fig. 18). The tumour itself consisted of dense relatively acellular fibrous tissue containing only a few plasma cells, lymphocytes, one or two eosinophils, a number of capillaries, and scattered pigment. On its inner side it projected directly into the vitreous, which appeared normal in this section, and on one side was continuous with a fibrous layer on the surface of its retinal margin. On its outer aspect the fibrous mass merged with proliferated pigment epithelium, but Bruch's membrane was intact and there was only a very scanty round cell infiltration in the underlying choroid (Fig. 19).

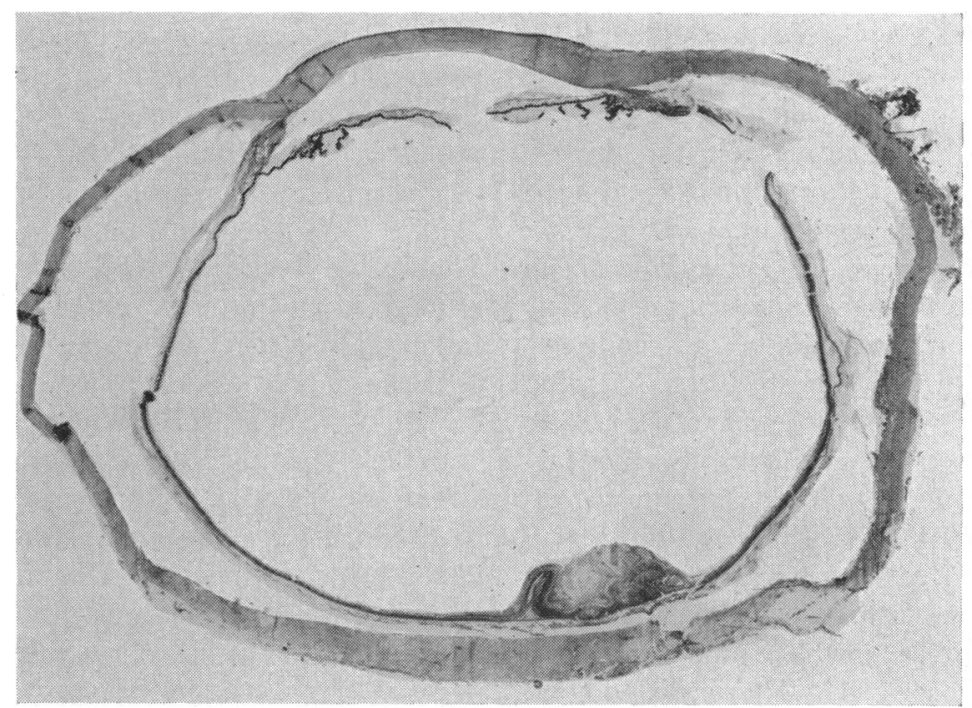

Fig. 18. - Case 4, initial section of right eye showing a fibrous granuloma at the macula. Larvae were not found in serial sections through this mass. Paraffin section. $\times 3.75$.

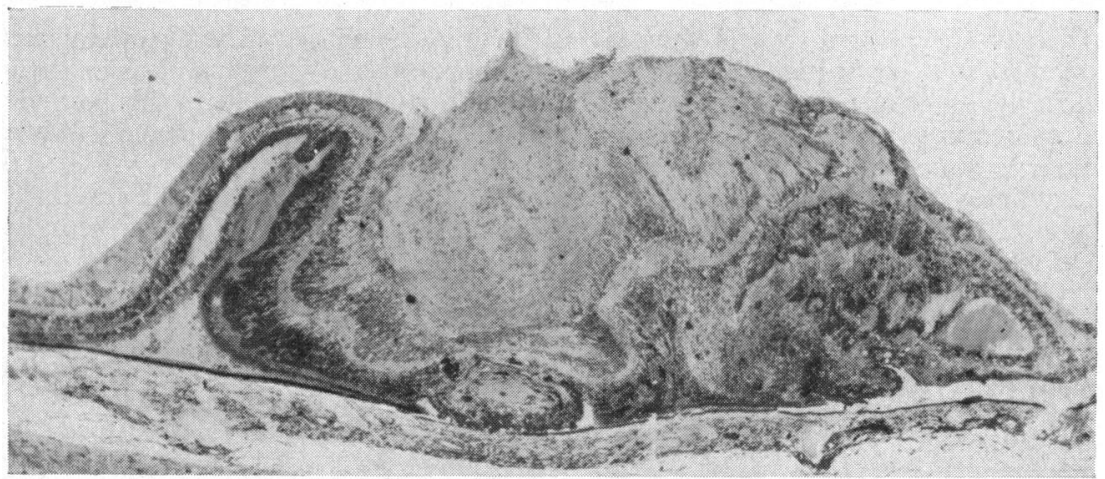

Fig. 19.- Higher-power view of lesion shown in Fig. 18. The retina is folded around the granuloma and there is only a mild chronic inflammatory infiltration in the subjacent choroid. $\times 24$. 
The section did not include the disc or optic nerve, and at this time it was not possible to correlate the histological picture with the clinical description of a tumour involving the optic nerve. The opinion given on this single section in 1956 was that the localized fibrous tumour probably arose from injury, and it was somewhat doubtfully categorized as a traumatic proliferative chorio-retinopathy. A history of injury was in fact obtained, the boy having struck his right eye against a door at the age of 18 months, and having been knocked unconscious by a falling bottle at the age of 2 years. However, the finding of a larva in Case 1, which presented a comparable histological picture, suggested a similar aetiology in this case, and the paraffin block containing the remainder of the eye was obtained in October, 1959 (about $3 \frac{1}{2}$ years after enucleation), through the kindness of Dr. Margaret Leslie, pathologist of the Killearn Hospital. Serial sections were made through this specimen and several new features were found. The fibrous tumour at the macula was seen to connect with a folded detachment of the retina (with subretinal exudate) which, together with the disc, was drawn towards the fibrous mass, thus explaining the clinical appearance of a lesion involving the optic nerve head (Fig. 20, opposite).

Secondly, a small eosinophilic abscess, containing hyaline necrotic material and numerous foreign-body giant cells, was found inferiorly in the extreme periphery of the vitreous immediately adjacent to the ciliary body (Fig. 21, opposite).

In the 186th and 187th sections the coiled longitudinal fragments of a nematode larva were found (Figs 22 and 23, overleaf). In none of the 320 sections examined was there any evidence of another larva in the eye, the macular mass being fibrous throughout. It would appear, therefore, that the macular region was the site of entry into the eye, where the larva must have lodged for some time before actively passing into the vitreous cavity to settle at the bottom of the anterior vitreous.

In view of these findings further inquiries were made. Previous illnesses were mumps at 2 years, German measles at $4 \frac{1}{2}$ years, frequent colds, and the injuries already described. There was no history of pulmonary or hepatic disturbances and the only family pet was a cat. A blood count showed no eosinophilia and no parasites were found in the faeces.

For an expert opinion on the larva the two sections were submitted to Dr. J. N. Oldham, who reported as follows:

"The two slides from Case 4 show a very definite nematode in longitudinal section. One shows the anterior part of the larva in two portions and is not so clear as the other in which the anterior portion of the larva is unbroken. It is possible in this second slide to get an accurate diameter measurement of $0.019 \mathrm{~mm}$., which is within the width range of Toxocara canis second-stage larva as given by Sprent (1958). It is also possible to make out something of the oesophageal structure and $/$ estimate that its length is about $0 \cdot 10$ or $0 \cdot 11 \mathrm{~mm}$. The range given by Sprent for the oesophageal length of $T$. canis second-stage larva is $0.082-0.121 \mathrm{~mm}$."

\section{Discussion}

Visceral Larva Migrans.-Histological examination of the retinal tumours of these four cases has shown that each is a solitary granuloma resulting from roundworm infestation, and in every case the parasite has been identified as the second-stage larva of the genus Toxocara, probably that of the dog ascarid, Toxocara canis. Thus they are all examples of ocular involvement 


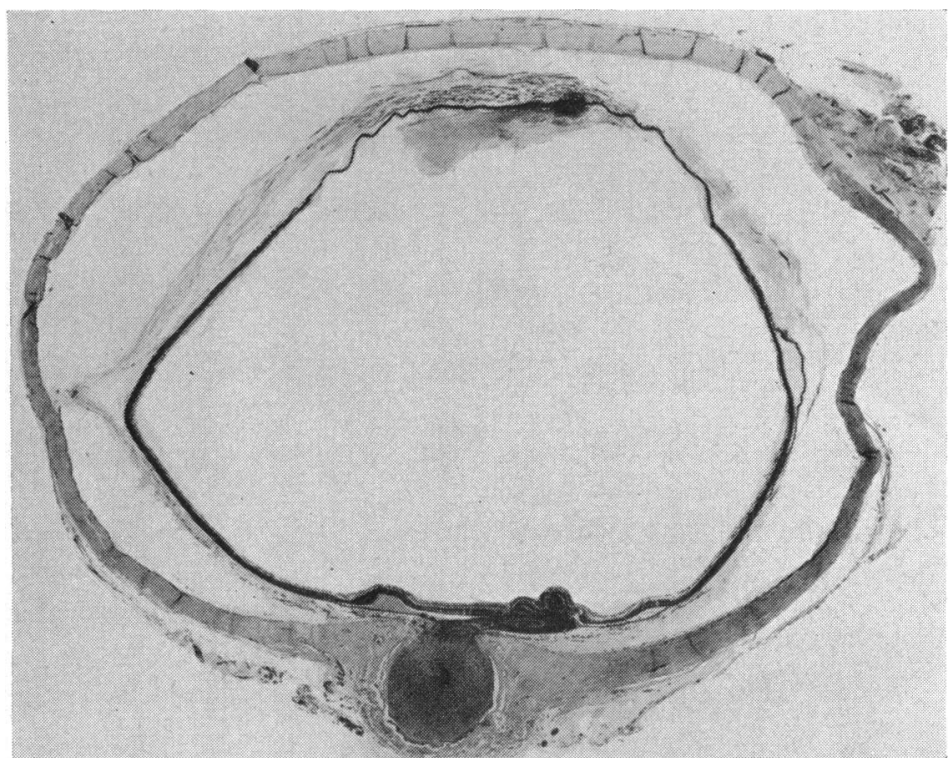

FIG. 20.-Case 4, further sections of the right eye showing a folded retinal detachment overlying the displaced disc. Anteriorly, immediately adjacent to the ciliary body, there is a small eosinophilic abscess containing giant cells and the fragments of a nematode larva. Paraffin section. $\times 3.75$.

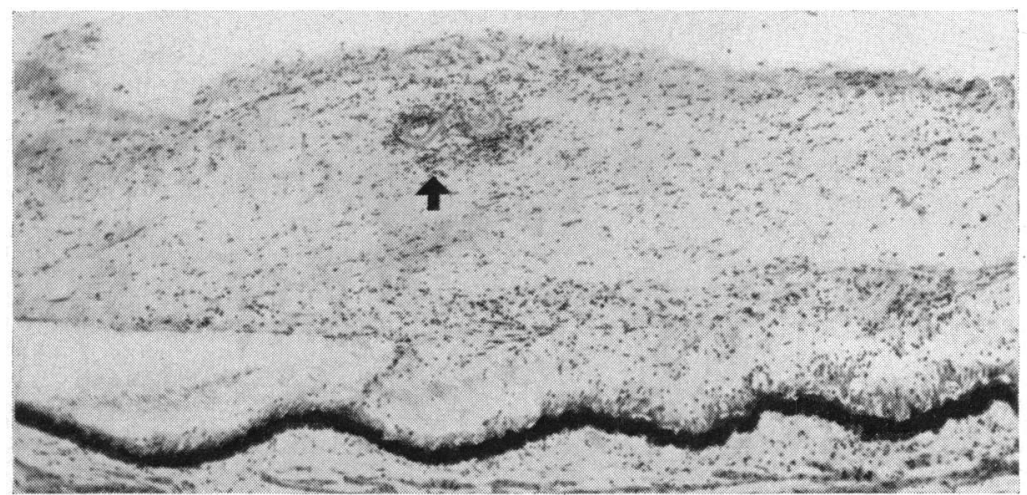

Fig. 21.-Higher-power view of eosinophilic abscess seen in Fig. 20, showing the coiled fragment of a nematode larva (arrow). $\times 56$.

in "visceral larva migrans" or "larval granulomatosis", terms applied to the clinical syndrome of childhood, which results from the invasion of human tissues by larvae of nematodes normally parasitic in lower animals (Beaver and others, 1952; Karpinski, Everts-Suarez, and Sawitz, 1956; Platou and Beaver, 1957).

At the present time the only parasites identified as causing this syndrome, which is characterized by marked and persistent eosinophilia, with constitutional symptoms, pneumonitis, and hepatomegaly, are the ascarids of 

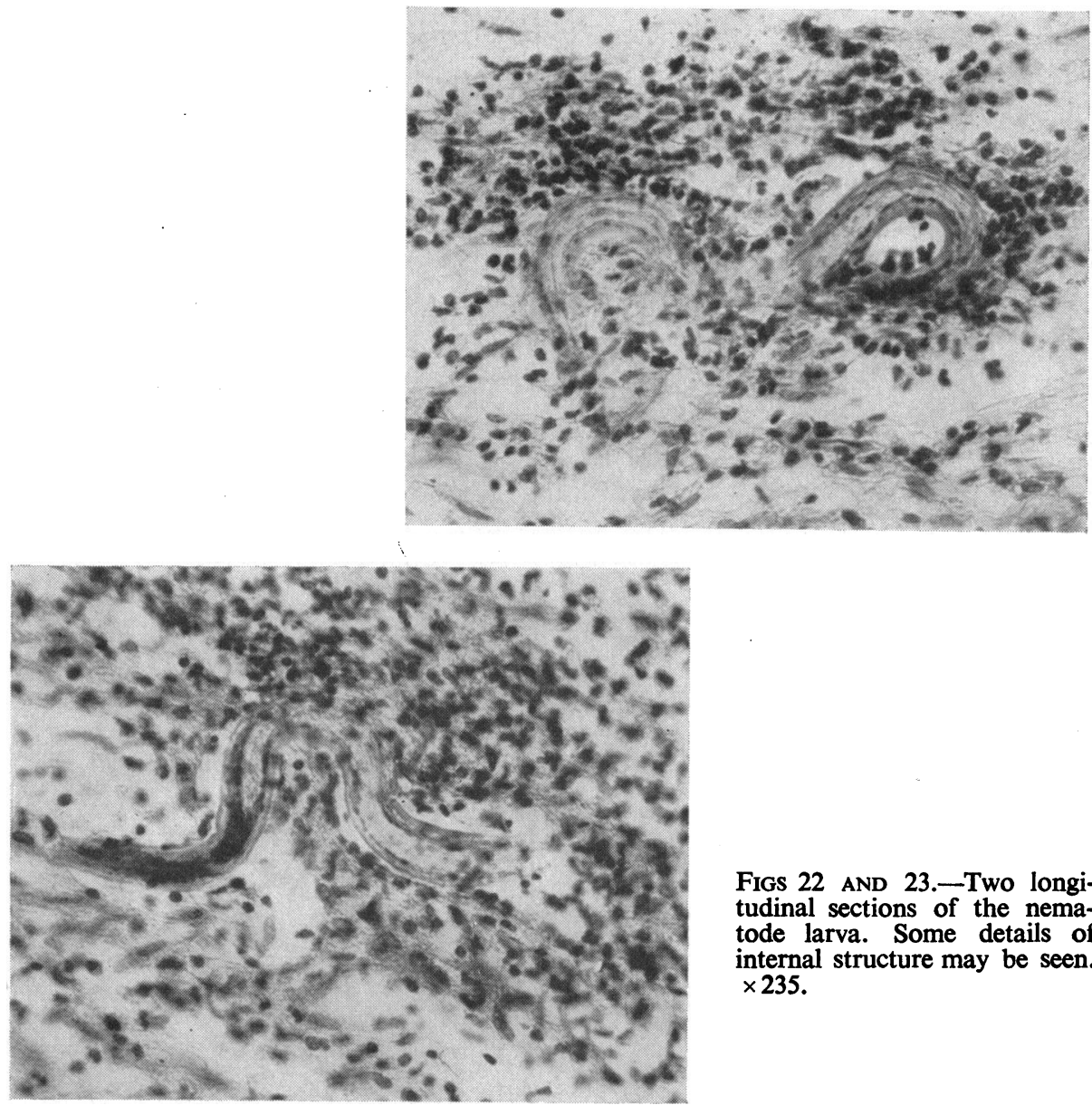

FIGS 22 AND 23.-Two longitudinal sections of the nematode larva. Some details of internal structure may be seen. $\times 235$.

the dog and cat, namely Toxocara canis (Belascaris marginata) and cati (Belascaris mystax), (Swartzwelder, 1941; Beautyman and Woolf, 1951; Beaver and others, 1952; Mendheim, Scheid, and Schmidt, 1952; Brill and others, 1953; Milburn and Ernst, 1953). Of these, Toxocara canis is believed to be more important, for it is said to be not only the commoner parasite but also the only one to have been identified with certainty in the reported cases; moreover, the typical syndrome has been reproduced in human volunteers by administering the larvae (Smith and Beaver, 1953). Recent investigations further suggest that larvae of these nematodes may be responsible for tropical eosinophilia (Gault and Webb, 1957).

Toxocara canis is the commonest cosmopolitan intestinal parasite of dogs, particularly of puppies, as indicated by some of the figures in the literature: 21 per cent. of 1,465 dogs in Indiana, U.S.A. (Ehrenford, 1957), 20 per cent. of dogs in Boston, U.S.A. (Heiner and Kevy, 1956), 13.5 per cent. of dogs 
in Marseilles (Solomon, 1933), 76.5 per cent. of 81 puppies in the Philippines (Yutuc, 1954), 21.8 per cent. of 174 dogs, with a maximum incidence in puppies up to one year old, in Melbourne, Australia (Pullar, 1946), and 82.87 per cent. of 100 dogs in Calcutta (Maplestone and Bhaduri, 1940). The only figures available for the United Kingdom are those of Lewis (1927), who found Toxocara canis in 16.3 per cent. of dogs and Toxocara cati in 61.8 per cent. of cats examined in Aberystwyth, Wales, of Nuttall and Strickland (1908), who found Toxocara in 70.8 per cent. of dogs in Cambridge, and of Brown and Stammers (1922), who demonstrated the ova of these helminths in 3 per cent. of faecal deposits in London streets.

Both species of Toxocara resemble other members of the family Ascarididae and, in their normal host, follow a life cycle paralleling that of their human counterpart, Ascaris lumbricoides; they are, however, much smaller, being only 3 inches long in their adult form. In man the parasite is unable to complete its life cycle, and it rarely, if ever, reaches the egg-laying stage in the human intestine (Dent and others, 1956); but once the ova of Toxocara have been swallowed, usually by children of dirt-eating age, they are capable of hatching out in the stomach and intestines, whence the larvae migrate through the intestinal wall into the blood and lymphatics to become widely disseminated throughout the body. This prolonged migration is responsible for the chronic eosinophilia, while the widespread visceral invasion, particularly of liver and lung, results in minute multiple granulomata. Access to the eye may be gained either via the ciliary vessels to the choroid or via the central retinal vessels to the retina and vitreous, both types of lesion having been observed. According to Sprent (1954), the larvae of Toxocara canis are particularly active borers.

Ocular Involvement.-The eyes examined by Wilder (1950) were from 46 patients originally diagnosed pathologically as cases of pseudoglioma, Coats's disease, or endophthalmitis; with few exceptions the patients were children of school or pre-school age, and in most cases the eyes had been enucleated for a suspected retinoblastoma. In serial sections from 24 of these specimens, she found evidence of nematode larvae, and in the remaining 22 she considered the intra-ocular reaction sufficiently characteristic to make a tentative diagnosis of nematode endophthalmitis. As already recounted, Nichols (1956a) then identified the larval fragments in four of these cases as Toxocara canis, which, together with the case of Irvine and Irvine (1959) and the four cases reported here, makes nine definitely established cases due to Toxocara reported in the literature so far. It would thus seem probable that the nematodes contained in Wilder's twenty remaining eyes were of the same nature. To Wilder's group of 22 cases believed to be due to nematode larvae because of the characteristic histological picture, we could add several current examples from our own material, and we share with her the impression that this disease will prove more common than is at present 
supposed. Nevertheless, it may now be wiser to confine any further reports to cases where the nematode larvae have actually been demonstrated, otherwise there would seem to be a danger of exaggerating the problem, or of side-tracking other important aetiological factors into wrong categories.

It is interesting that the four cases reported here are not only unique in being the first to be reported in Great Britain, but are also exceptional in the type of lesion presenting. In Cases 1, 2, and 3, there was an isolated retinal tumour with no other ocular change, apart from vitreous exudate and a subjacent choroidal reaction. In only one of Wilder's cases was the lesion comparable to this, ${ }^{*}$ most of the reactions being much more severe, presenting a picture of external exudative or haemorrhagic retinitis, with retinal detachment and abscess formation. Similarly, in the case of Irvine and Irvine (1959), the nematode larva was found in an eosinophilic abscess at the ora serrata and the retina was detached.

Although it is important from the clinical and pathological points of view to know that migrating larvae can give rise to solitary retinal tumours with little evidence of inflammation, this type of lesion is, of course, no more than a variety of nematode endophthalmitis, the differing picture depending upon the site of lodgement of the larva, the severity of the individual reaction, and the stage at which the eye is examined. Thus, a combination of reactions is shown in our Case 4, wherein the nematode, in entering the eye, gave rise to a retinal granuloma, but subsequently passed into the vitreous cavity to produce an eosinophilic abscess in the anterior vitreous, as in the case of Irvine and Irvine (1959).

Histological Diagnosis.-This can be made with certainty only when the larvae have been demonstrated (even capsular fragments may be simulated by exudate or other hyaline material), and this usually entails a prolonged search through many serial sections, often running into hundreds. The possibility of their presence will have been suggested by the unexplained granulomatous reaction in the eye of a young person, by the eosinophilic infiltration or eosinophilic abscesses, by the presence of foreign-body giant cells or hyaline capsular fragments of the appropriate size, and by fibrinoid necrosis in the immediate vicinity of the larva. The capsular fragments show up particularly well in slides stained with the periodic-acid-Schiff method. Curiously, the right eye was affected in all our cases.

The identification of Toxocara larvae and their differentiation from those of other nematodes is based on the relative diameters of the body, the presence or absence of lateral alae and posterior excretory columns, and the type of intestine. Diagnosis can generally be made on the basis of one transverse section at the mid-gut level, where the significant features are single lateral

* As seen in Wilder (1950). Trans. Amer. Acad. Ophthal. Otolaryng., 55, 99, Fig. 14. 
alae formed by sharp foldings of the cuticle in the lateral line, and an intestine, without lumen, compressed by two large prominent posterior excretory columns which are eosinophilic and non-nucleated (Fig. 24a,b). The larva of $T$. canis can be distinguished from $T$. cati only by its slightly greater diameter. For further details the reader is referred to the excellent studies of Sprent (1954, 1955, 1958), Nichols (1956a,b), Dent and others (1956), and Schacher (1957).

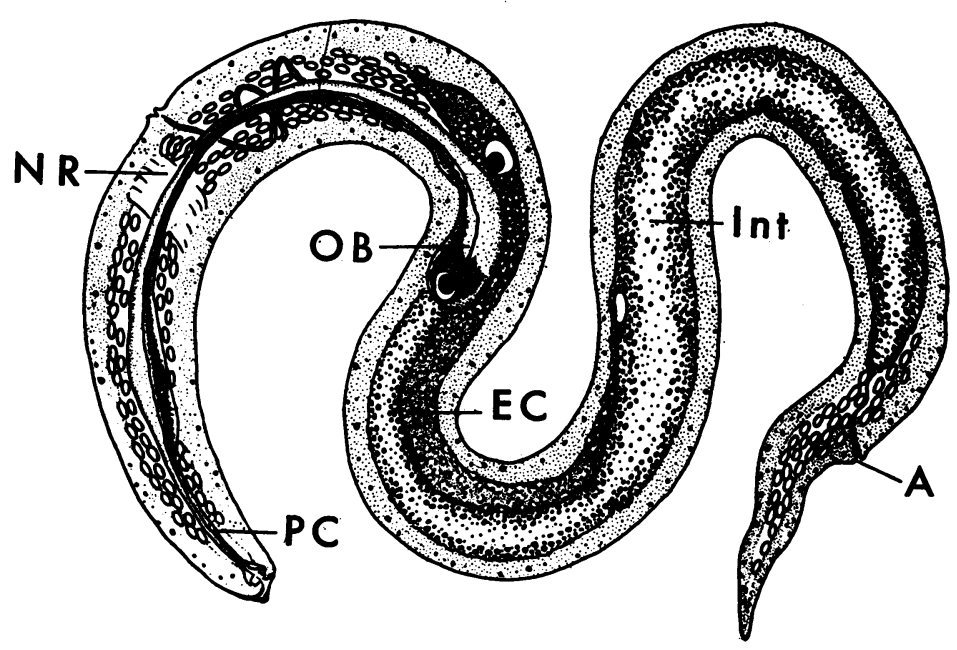

FIG. 24 (a).-Lateral view of second-stage larva of Toxocara canis.

PC, procorpus; NR, nerve ring; OB, oesophageal bulb; EC, excretory column; Int, intestine; A, anus.

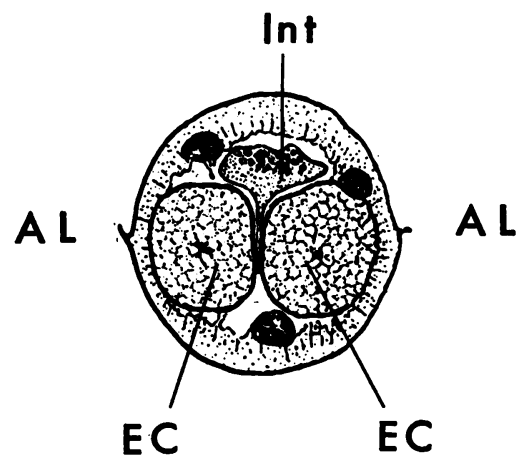

Fig. $24(b)$.- Transverse section at mid-gut level of second-stage larva of Toxocara canis.

$\mathrm{AL}$, lateral alae; EC, excretory column; Int, intestine.

(After R. L. Nichols (1956a). J. Parasitol., 42 359, plate 1, by courtesy of the editors and publishers).

It is probable that the larvae are least likely to be found in lesions where the inflammatory reaction is acute, since they may be destroyed by digestive ferments, and are most likely to be discovered in cases where they have become encapsulated. It is remarkable that the larvae have been known to survive encapsulation in the tissues for at least 2 years, this type of tissue reaction serving rather to protect than to destroy them (Beaver, 1957); but sooner or later they die and the lesions may heal by fibrosis. The possibility 
that this fortunate termination may occur in the eye emphasizes the need for differentiating the lesion from a neoplasm.

Clinical Diagnosis.-This is, unfortunately, extremely difficult because a history of dirt-eating, or of contact with dogs, or of fever and general debility in childhood are barely sufficiently distinctive; stool examinations are unhelpful, since the life-cycle of the worm is not completed; skin tests and serological tests with specific antigens are not yet reliable (Heiner and Kevy, 1956; Fellers, 1953); and $x$-ray examination has not proved of value (Dent and others, 1956).

In investigation, the eosinophil count is the most valuable guide and should be carried out in every case of endophthalmitis or suspected case of neoplasm or Coats's disease in childhood, because a definite eosinophilia, together with fever, debility, and pulmonary or hepatic involvement, is highly suggestive of visceral larva migrans. Yet the degree of eosinophilia, like the severity of the clinical symptoms, is apparently proportionate to the severity of the infestation (Smith and Beaver, 1953), so that a relatively isolated intra-ocular lesion may be unaccompanied by any blood changes, or indeed by any other signs or symptoms. In more severe infestation the eosinophilia may be pronounced (between 40 and 60 per cent. of the total white count) and may persist for several months at least-as has been reported in a patient (Dent and others, 1956) and in a human volunteer (Chaudhuri and Saha, 1959).

As will be seen in the four cases here described, there would have been very little to suggest a parasitic infection. Only a slight eosinophilia (7 per ${ }^{*}$ cent.; 490 per c.mm.) was found in Case 3 and none in Case 2 (in Cases 1 and 4 a differential blood count was not carried out at the time of enucleation), and all four patients were apparently healthy with no history of unexplained pyrexia. In Case 1 the history of pneumonia 4 years before enucleation may be significant. Similarly, in the case reported by Irvine and Irvine (1959), there was only a very slight eosinophilia (6 per cent.; 354 per c.mm.) and "a system review was non-contributory".

The incidence of visceral larva migrans in Great Britain is completely unknown, but, unless it can be shown that the Toxocara larvae have a predilection for the eye, as they apparently have for the mouse brain (Smith and Beaver, 1953; Sprent, 1955), it must certainly be commoner than these four isolated cases would suggest. Nor can its aetiological importance in endophthalmitis as yet be assessed; this will involve a laborious examination of serial sections of all the obscure pseudo-tumours in our collection and of cases coming to the department in future. Meanwhile it is hoped that this report will emphasize the need for further research into the role of hostforeign parasites in ocular disease, and will at the same time underline the potential danger-albeit remote- of household pets to children. Moreover, this risk of intimate contact with cats and dogs applies not only to Toxocara, but also to other intestinal parasites of world-wide distribution, such as 
Ancylostoma caninum, a common hookworm of dogs and cats, which may be another cause of visceral larva migrans (Nichols, 1956b), and Dipylidium caninum, the common tapeworm of cats and dogs, which has occasionally been found in man-particularly children, and to the well-known Echinococcus granulosum. It has even been suggested that young dogs and cats in close contact with children should be "dewormed" at regular intervals up to 2 years of age, whereafter Toxocara infection is infrequent in these animals (Smith and Beaver, 1953). Indeed prevention is the only line of attack, for there is at present no drug known to be effective against the migrating larvae of Toxocara.

\section{Summary}

(1) Four cases of retinal granuloma due to Toxocara canis-the common nematode of the dog-are described. Ocular disease due to host-foreign parasites has not previously been reported in Great Britain, although several cases have been described in America.

(2) These are examples of ocular involvement in "visceral larva migrans", a term applied to the clinical syndrome of childhood, which results from the invasion of human tissues by larvae of nematodes normally parasitic in lower animals. The only parasites so far identified as causing this syndrome are the ascarids of the dog and cat, Toxocara canis and $T$. cati.

(3) Every case presented with a solitary retinal tumour, a type of lesion not previously recognized, and since a retinal neoplasm is so closely mimicked this would appear to be a clinico-pathological entity of importance.

(4) The incidence of visceral larva migrans in Great Britain is completely unknown but, in the absence of any evidence that the larvae have a predilection for the eye, it is presumably more common than these four isolated cases would suggest.

(5) In clinical diagnosis there is no investigation of certain value, but an eosinophil count may be helpful, and should be carried out in every case of endophthalmitis, or suspected case of neoplasm, or of Coats's disease in childhood, in all of which migrating larvae should be considered as a possible cause.

(6) For histological diagnosis, any eye of a young person showing an unexplained granulomatous reaction, particularly with an eosinophilic component, should be examined in serial section.

(7) There is no drug known to be effective against the migrating larvae of Toxocara and prevention is at present the only line of attack; it should therefore be remembered that there is a potential danger to children in close contact with household pets. 
For kindly providing the case histories and for giving me permission to publish them, and for so readily obtaining follow-up information, I am considerably indebted to the numerous clinicians and pathologists individually mentioned in the case reports. It is a pleasure to acknowledge the expert assistance of Professor J. J. C. Buckley and Dr. J. N. Oldham in identifying the parasites, and I should also like to thank Messrs G. E. Knight, V. J. Elwood, A. McNeil and P. Aldred for technical assistance, Miss E. FitzGerald for secretarial help, and the Medical Illustration Department of the Institute of Ophthalmology, for some of the illustrations.

\section{REFERENCES}

Beautyman, W., and Woolf, A. L. (1951). J. Path. Bact., 63, 635.

BeAver, P. C. (1957). Amer. J. trop. Med. Hyg., 6, 433.

, Snyder, C. H., Carrera, G. M., Dent, J. H., and Lafferty, J. W. (1952). Pediatrics, $9,7$.

Brill, R., Churg, J., and Beaver, P. C. (1953). Amer. J. clin. Path., 23, 1208.

Brown, H. C., and Stammers, G. E. F. (1922). Lancet, 2, 1165.

Chaudhuri, R. N., and SAHA, T. K. (1959). Ibid., 2, 493.

Dent, J. H., and CARrera, G. M. (1953). J. Louisiana med. Soc., 105, 275. , Nichols, R. L., Beaver, P. C., Carrera, G. M., and Staggers, R. J. (1956). Amer. J. Path., 32, 777.

EHRENFORD, F. A. (1957). Amer. J. trop. Med. Hyg., 6, 166.

Fellers, F. X. (1953). Amer. J. Dis. Child., 86, 767.

GAULT, E. W., and WebB, J. K. G. (1957). Lancet, 2, 471

HeINER, D. C., and KeVy, S. V. (1956). New Engl. J. Med., 254, 629.

Irvine, W. C., and Irvine, A. R. (1959). Amer. J. Ophthal., 47, No. 5, (Part II), p. 185.

KarPINSKi, F. E., Jr., Everts-Suarez, E. A., and SaWrtz, W. C. (1956). Amer. J. Dis. Child., 92, 34.

LEWIS, E. A. (1927). J. Helminth., 5, 171.

MAPlestone, P. A., and BHADURI, N. V. (1940). Indian J. med. Res., 28, 595.

MENDHEIM, H., SCHEID, G., and SCHMIDT, J. (1952). Z Z. Tropenmed. Parasit., 3, 368.

Milburn, C. L., and ERnst, K. F. (1953). Pediatrics, 11, 358.

Nichols, R. L. (1956a). J. Parasit., 42, 349 (1956b). Ibid., 42, 363.

NutTall, G. H. F., and Strickland, C. (1908). Parasitology, 1, 261.

Platou, R. V., and Beaver, P. C. (1957). Acta paediat., 46, 64.

Pullar, E. M. (1946). Aust. vet. J., 22, 85.

SCHACHER, J. F. (1957). J. Parasit., 43, 599.

Smith, M. H. D., and Beaver, P. C. (1953). Pediatrics, 12, 491.

Solomon, S. G. (1933). J. Helminth., 11, 157.

SPRENT, J. F. A. (1954). J. Parasit., 40, 608. (1955). Parasitology, 45, 31. (1958). Ibid., 48, 184 .

SWARTZWELDER, J. C. (1941). J. trop. Med. Hyg., 44, 61.

Wilder, H. C. (1950). Trans. Amer. Acad. Ophthal. Otolaryng., 55, 99.

Yutuc, L. M. (1954). J. Parasit., 40, No. 5, Sect. 2 (Suppl.), p. 18. 